\title{
AN "EXTENSION" OF THE CARBOHYDRATE BINDING SPECIFICITY OF CONCANAVALIN A
}

\author{
I. J. GOLDSTEINa, CHERYL M. REICHERTa, A. MISAKIa AND P. A. J. GORINb \\ aThe Department of Biological Chemistry, The University of Michigan, Ann Arbor. Mich. 48ro4
} (U.S.A.) and brairie Regional Laboratory, Saskatoon, Saskatcherean (Canada)

(Recoived May 2nd, I973)

SUMMARY

Evidence based on the quantitative precipitin method and hapten inhibition technique demonstrates that concanavalin A may interact with internal 2 - $O$-linked $\alpha$-D-mannopyranosyl residues as may occur in glycoproteins and polysaccharides.

Concanavalin A, the sugar-binding protein of the jack bean (Canavalia ensiformis), has proved to be a valuable tool in many areas of the biological sciences ${ }^{1}$. Essential to all of its diverse biological properties is the ability of this protein to interact specifically with a select group of carbohydrate moieties ${ }^{2}$.

By means of the quantitative precipitin method and the techniques of hapten inhibition and equilibrium dialysis it was established that the combining sites of concanavalin A are most complementary to $\alpha$-D-mannopyranosyl residues but will also bind $\alpha$-D-glucopyranosyl (and its 2 -acetamido-2-deoxy derivative) and $\beta$-Dfructofuranosyl units ${ }^{3-8}$. We have proposed that unmodified hydroxyl groups at $\mathrm{C}-3$, C 4 and C-6 of the D-arabino-hexopyranosyl configuration (Mäkelä's group 3 sugars ${ }^{9}$ ) appear to represent the minimum structural features required for saccharide binding to concanavalin $\mathrm{A}^{3-6}$. In addition we postulated that concanavalin $\mathrm{A}$ precipitates certain carbohydrate-containing macromolecules by interaction with specific glycosyl moieties situated at terminal, non-reducing oligo- and polysaccharide chain ends ("chain-end mechanism") $3-8,10,11$.

It now appears necessary to modify our original concept of an exclusive "chainend mechanism" to account for all concanavalin A-carbohydrate interactions. The experimental observation which provided the first exception to our hypothesis was the finding that sophorose $(2-O-\beta$-D-glucopyranosyl-D-glucose) inhibited concanavalin A-dextran interaction ${ }^{12}$. All our previous studies had shown that only $\alpha$-linked Dglucose- and D-mannose-containing disaccharides bind to concanavalin A. This was the first indication that internal sugar residues could bind to the protein, for it was shown unequivocally that concanavalin A binds to the reducing D-glucosido moiety of this $\beta$-glucobiose. 
Some years ago, Hehre ${ }^{13,14}$ and Suzuki and Hehre ${ }^{15}$ raised the same question when they pointed out that 2-O-substituted $\alpha$-D-glucopyranosyl residues which occur in many dextrans possess the configurational features which we suggested were necessary for interaction with concanavalin A (unmodified hydroxyl groups at $\mathrm{C}-3$, $\mathrm{C}-4$ and $\mathrm{C}-6$ of $\alpha$-D-glucopyranosyl residues).

Furthermore, it has been observed that certain glycopeptides lacking terminal $\alpha$-D-glucopyranosyl or $\alpha$-D-mannopyranosyl residues inhibit erythrocyte hemagglutination ${ }^{16}$ by concanavalin $\mathrm{A}$. Similar studies which implicate internal residues of cell receptor glycoproteins have been conducted by Kornfeld and his colleagues ${ }^{\mathbf{1 7}}$ on phytohemagglutinins from Lens culinaris, Agaricus bisporus ${ }^{\mathbf{1 8}}$ and Robinia pseudoaccacia $^{19}$.

In this paper we provide the evidence which demonstrates that concanavalin A may interact with internal $(I \rightarrow 2)$-linked $\alpha$-D-mannopyranosyl residues.

Concanavalin A was prepared by the method of Agrawal and Goldstein ${ }^{20}$. The procedures for quantitative hapten inhibition ${ }^{3}$ and agar gel diffusion ${ }^{21}$ have been described previously. Quantitative precipitin analyses were performed as previously reported $^{8}$ with the exception of smaller reaction volumes ( $\mathrm{r} . \mathrm{O} \mathrm{ml}$ ) and a longer incubation period (I week). Oligosaccharides were isolated as described ${ }^{22,23}$ except for $2-O-\beta$ D-glucopyranosyl-D-mannose which was synthesized in this laboratory by a procedure which will be described elsewhere. Methyl $\alpha$-D-glucopyranoside and methyl $\alpha$-Dmannopyranoside were purchased from Pfanstiel Laboratories, Waukegan, Illinois. Klebsiella K-24 (ref. 24) was obtained from Prof. Guy Dutton, University of Vancouver, Canada; Klebsiella K-57 (ref. 25) from Prof. Bengt Lindberg, University of Stockholm, Sweden and Klebsiella K-II from Dr S. Stirm, Max-Planck Institut für Immunbiologie, Freiburg, W. Germany.

Both of the trisaccharides shown in Fig. I are good inhibitors of the concanavalin A-dextran B-I355-S precipitation reaction despite the fact that neither possesses a nonreducing $\alpha$-D-mannopyranosyl terminus. Inasmuch as $D$-galactose and its derivatives do not bind to concanavalin A (refs $3-6$ ) we may infer that 2 - $O$-substituted $\alpha$-D-mannopyranosyl residues can bind to the active sites of the protein, a not so surprising conclusion when it is recalled that the $\mathrm{C}-3, \mathrm{C}-4$ and $\mathrm{C}-6$ hydroxyl groups are still available for interaction. It may also be noted that 2-O-methyl-D-mannose was shown to be equivalent to $\mathrm{D}$-mannose as an inhibitor of the concanavalin A system ${ }^{6}$.

Borohydride reduction of trisaccharide $\mathrm{A}[\alpha-\mathrm{D}-\mathrm{Gal}-P(\mathrm{I} \rightarrow 2)-\alpha-\mathrm{D}-\mathrm{Man}-P(\mathrm{I} \rightarrow 2)-\mathrm{D}-$ Man], which contains two $\alpha$ - $(\mathrm{I} \rightarrow 2)$-linked D-mannose units, affords the corresponding trisaccharide alditol. The latter still contains an internal $\alpha$ - $(I \rightarrow 2)$-D-mannopyranosyl unit and, although less potent than the parent trisaccharide $A$, nevertheless inhibits to the same extent as methyl $\alpha$-D-mannopyranoside (Fig. I).

The two $\beta$-linked disaccharides (2-O- $\beta$-D-mannopyranosyl-D-mannose and $2-O-\beta$-D-glucopyranosyl-D-mannose) inhibited concanavalin $\mathrm{A}$-dextran interaction to a much lesser extent than methyl $\alpha$-D-mannopyranoside and $2-O-\alpha$-D-mannopyranosylD-mannose: the latter disaccharide contains two D-mannosyl units each of which is potentially capable of binding to concanavalin A (cf. ref. 26).

An alternate approach to assessing the potential of 2 - $O$-substituted $\alpha$-D-mannopyranosyl residues as receptor sites for concanavalin A involves precipitation studies with macromolecules of known constitution. The repeating units of the polysaccharides of several Klebsiella species have been elucidated. Some of these polysaccharides 


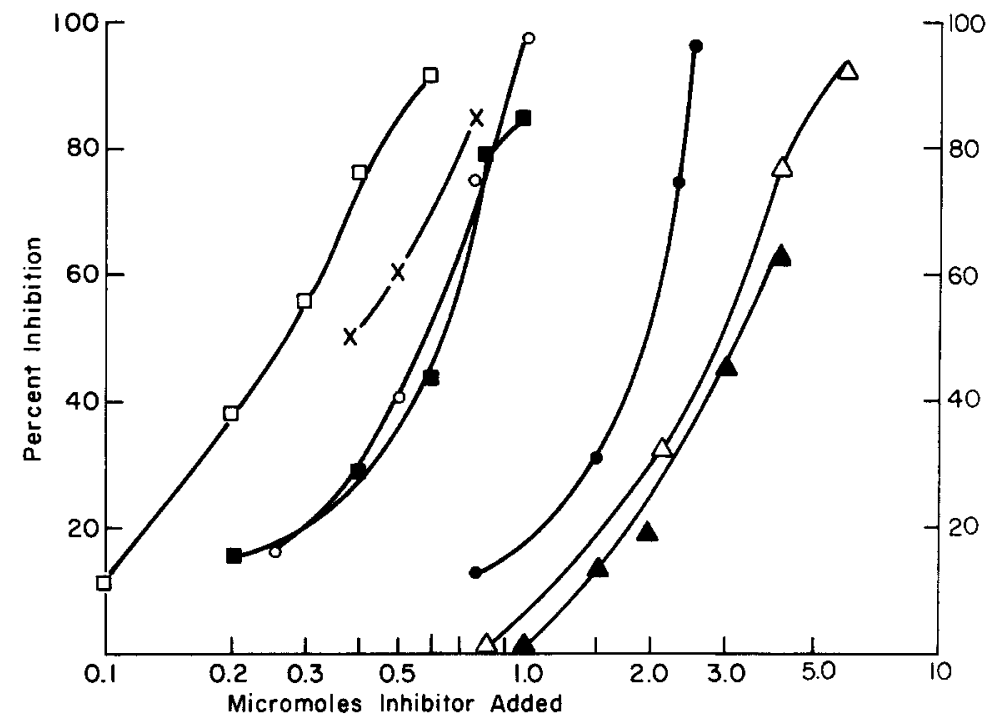

Fig. 1. Inhibition by saccharides of concanavalin A-dextran B-1355-Sinteraction. Each tube contained concanavalin $\mathrm{A}(340 \mu \mathrm{g})$, dextran $\mathrm{B}-1355-\mathrm{S}(600 \mu \mathrm{g})$ and inhibitor as noted in a total volume of $3.0 \mathrm{ml} . \square, O-\alpha$-D-galactopyranosyl-( $\square \rightarrow 2)-O-\alpha-\mathrm{D}$-mannopyranosyl-( $1 \rightarrow 2)$-D-mannose (trisaccharide A); $x, \quad O$ - $\alpha$-D-galactopyranosyl- $(\mathrm{I} \rightarrow 6)-O-\alpha$-D-mannopyranosyl- $(1 \rightarrow 2)$-D-mannose; $O$, methyl $\alpha$-D-mannopyranoside; $\mathbf{D}, O$ - $\alpha$-D-galactopyranosyl- $(\mathrm{I} \rightarrow 2)-O$ - $\alpha$-D-mannopyranosyl- $(\mathrm{I} \rightarrow 2)-$ $\mathrm{D}$-mannitol (reduced trisaccharide A); 0 , methyl $\alpha$-D-glycopyranoside; $A$, 2- $O$ - $\beta$-D-glucopyranosyl-D-mannose; $\boldsymbol{\Delta}, 2-O-\beta-D-m a n n o p y r a n o s y l-D-m a n n o s e$.

possess internal 2-O-linked $\alpha$-D-mannopyranosyl units as the only saccharide capable of binding to concanavalin $A$. In several instances we have been able to demonstrate reactivity of concanavalin A with certain Klebsiella polysaccharides. These include $\mathrm{K}-24$ and $\mathrm{K}-57$. (It is of great interest that $\mathrm{K}-24$, reported to contain one $O$-acetyl group $^{24}$ did not give a precipitate with concanavalin A until we had treated it with o.I $\mathrm{M}$ aq. NaOH.) Fig. 2 presents the photograph of an Ouchterlony two dimensional agar gel diffusion plate showing the reaction of Klebsiella K-24, K-I I and K-57. As expected, the polysaccharide from Klebsiella K-I I which contains neither D-mannose nor D-glucose failed to react with concanavalin A.

Fig. 3 shows the precipitin curve generated when a constant amount of concanavalin $A(46 \mu \mathrm{g} \mathrm{N})$ interacts with increasing amounts of K-24. The inset in Fig. 3 shows the solubility of the concanavalin A-polysaccharide complex. The solubility of the concanavalin A-K-24 precipitate is very high ( $5 \mu \mathrm{g} \mathrm{N} / \mathrm{ml}$ ). This taken together with the great ease with which methyl $\alpha$-D-mannopyranoside inhibits the concanavalin A-K-24 precipitation reaction (0.036 $\mu$ mole glycoside for $50 \%$ inhibition compared to $0.6 \mu$ mole for the concanavalin A-dextran B-I355-S system ${ }^{4}$ ) leads us to suggest that the binding of concanavalin A to the isolated 2 -O-linked $\alpha$-D-mannopyranosyl residues in $\mathrm{K}-24$ may be quite weak.

These experiments suggest that 2 -O-linked $\alpha$-D-mannopyranosyl residues (and almost certainly $2-O$-linked $\alpha$-D-glycopyranosyl units), when accessible, may serve as receptor sites for concanavalin A. Furthermore, when $\alpha$ - $(\mathrm{I} \rightarrow 2)$-linked $\alpha$-D-mannopyranosyl residues occur in sequence they appear to be more effective as concanavalin A receptors than when they occur in isolation (cf. ref. 26). 

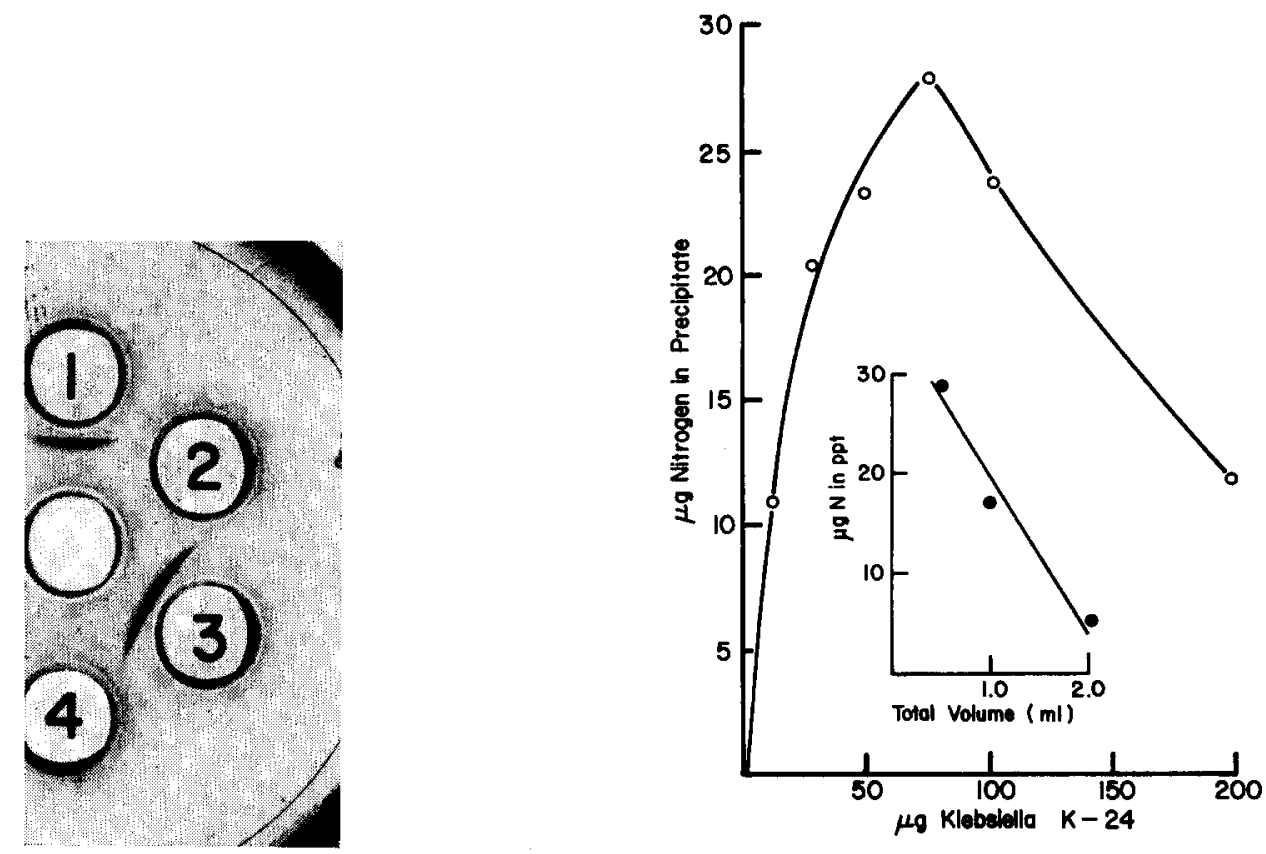

Fig. 2. Two-dimensional agar gel diffusion patterns. Central well: concanavalin A $(4 \mathrm{mg} / \mathrm{ml})$. Well I, Klebsiella K-24 (I.0 mg/ml); 2, Klebsiella K-I I (1.0 mg/ml); 3, Klebsiella K-57 (o.66 mg/ ml); 4, saline control.

Fig. 3. Quantitative precipitation curve of Klebsiella K-24 polysaccharide with concanavalin A. Concanavalin A, $46 \mu \mathrm{g}$ of nitrogen per tube. Inset shows the effect of volume on concanavalin A-Klebsiella $\mathrm{K}-24$ polysaccharide precipitation. Concanavalin A, $46 \mu \mathrm{g}$ of nitrogen; Klebsiella $\mathrm{K}-24$ polysaccharide, $75 \mu \mathrm{g}$.

\section{ACKNOWLEDGEMENTS}

This work was supported in part by N.I.H. Research Grant AM-IoI7I and U.S.P.H.S. Training Grant GM-oor87.

\section{REFERENCES}

I Sharon, N. and Lis, H. (1972) Science I77, 949-959

2 Goldstein, I. J. (I972) in Methods in Carbohydrate Chemistry (Whistler, R. L. and BeMiller, J. N., eds), Vol. VI, p. Io6, Academic Press, New York

3 Goldstein, I. J., Hollerman, C. E. and Smith, E. E. (I965) Biochemistry 4, 876-883

4 So, L. L. and Goldstein, I. J. (1967) J. Immunol. 99, I 58-163

5 Smith, E. E. and Goldstein, I. J. (1967) Avch Biochim. Biophys. I 2 I, 88-95

6 Poretz, R. D. and Goldstein, I. J. (I970) Biochemistry 9, 2890-2896

7 So, L. L. and Goldstein, I. J. (I968) Biochim. Biophys. Acta I65, 398-404

8 So, L. L. and Goldstein, I. J. (1967) J. Biol. Chem. 242, I6I 7-1622

9 Mäkelä, O. (1957) Studies in Hemagglutinins of Leguminosae, Weilin and Göös, Helsinki

ro Goldstein, I. J., Hollerman, C. E. and Merrick, J. M. (I965) Biochim. Biophys. Acta 97, 68-76

I I Smith, E. E., Gunja-Smith, Z. H. and Goldstein, I. J. (I968) Biochem. J. I07, 7I 5-724

I 2 Goldstein, I. J., Iyer, R. N., Smith, E. E. and So, L. L. (I967) Biochemistry 6, 2373-2377

I 3 Hehre, E. J. (1960) Bull. Soc. Chem. Biol. 42, I $5^{81-1585}$

I 4 Hehre, E. J. (I964) Kagaku No Royoiki 9, 454-455

I5 Suziki, H. and Hehre, E. J. (I964) Arch. Biochem. Biophys. I04, 305-3I3

I6 Toyoshima, S., Fukuda, M. and Osawa, T. (I972) Biochemistry I I, 4000-4005 
17 Kornfeld, S., Rogers, J. and Gregory, W. (1971) J. Biol. Chem. 246, 05810580

18 Presant, C. A. and Kornfeld, S. (1972) J. Biol. Chem. 247,6937-6945

19 Leseney, A. M., Bourrillon, R. and Kornfeld, S. (1972) Arch. Biochem. Bioph.15. 15.3, $831-8.30$ 20 Agrawal, B. B. L. and Goldstein, I. J. (rg65) Biochem. J.90, $23 C^{\circ} \cdot 25 \mathrm{C}$

2 I Goldstein, I. J. and So, L. L. (1965) Arch. Biochen. Biophys. I I , 407 414

22 Gorin, P. A. J., Spencer, J. F. T. and Magus, R. J. (1969) Can. J. Chem. 47, 3500-3576,

23 Gorin, P. A. J. and Spencer, J. F. T. (1968) Can. J. Chem. 46, 2299-2304

24 Choy, Y. M., Dutton, G. G. S. and Zanlungo, A. B. (197.3) Can. J. Chem., in the press

25 I indberg, B., Lönngren, J. and Nimmich, W. (1972) Acta Chem. Scand. 26, 2231-2236

26 So. I. T. and (iolklstein, I. J. (1968) J. Biol. Chem. 243, 2003-2007 